Session TA1-2

\title{
Two Visual Basic Modules for Teaching Propulsion
}

\author{
X. Chang Li, Kendrick Aung \\ Mechanical Engineering Department, Lamar University
}

\begin{abstract}
This paper describes the development of two Visual Basic modules that can be used in a typical propulsion course. The modules follow the design procedures outlined in the book by Cumpsty ${ }^{1}$ and are written in Visual Basic programming language to provide a Graphical User Interface (GUI). The modules deal with the design and analysis of two types of aircrafts: a large commercial airplane such as Boeing Dreamliner and a fighter aircraft such as F-16 or F18. Since the design requirements of these two types of aircraft are completely different, the students can use these modules to compare and contrast the two designs using these modules. The modules will be freely available to the interested educators and community through a web site.
\end{abstract}

\section{Introduction}

Propulsion is an important course in the study of engineering disciplines such as aerospace engineering, aeronautics, and mechanical engineering. There are some teaching tools related to propulsion available on the web such as NASA Beginner Guide to Propulsion web site ${ }^{2}$. The site is developed to facilitate learning basic principles of propulsion for K-12 education. In addition, commercial propulsion software such as GECAT Graphical Engine Cycle Analysis Tool from ManTech Corporation ${ }^{3}$ is also available. However, the commercial software is costly and is not intended for teaching purposes. Therefore, it seems that there is a need for a simple GUI based tool for design and analysis of an aircraft propulsion system suited for learning purposes. In addition, increased enrollment in the Department of Mechanical Engineering prompted the faculty members to develop new classes for undergraduate and graduate students. The authors plan to offer a Propulsion course in the Fall 2009 and it seems that a GUI based computational tool will be useful to the students in the new class. As a result, the authors have developed two Visual Basic modules that can be used in a typical propulsion course for aircraft propulsion system.

The authors have decided to use the design procedures outlined in the book by Cumpsty ${ }^{1}$ as these design sheets provide a step-by-step computation of various design variables based on the user input. Visual Basic is chosen as the programming language for the modules as both authors are well-versed in programming the language and it is relatively easy to build a graphical user interface (GUI) for the module. The topics in Cumpsty's book ${ }^{1}$ are divided along two themes: one for the design of engines for a new 600-seat aircraft and another for the design of engines for a New Fighter Aircraft. As a result, two modules were developed to facilitate two different types of engines required for the commercial aircraft and fighter aircraft respectively. Table 1 below (taken from Cumpsty's Table 13.2) shows clearly the different characteristics of commercial and fighter aircrafts.

Proceedings of the 2009 ASEE Gulf-Southwest Annual Conference Baylor University

Copyright $\left({ }^{\circ}\right.$ 2009, American Society for Engineering Education 
Table 1 Different characteristic of Boeing 747 and F-16 fighter aircrafts

\begin{tabular}{|l|c|c|}
\hline Characteristics & $747-400$ & F-16 \\
\hline Take-off Thrust/max. take-off weight & 0.25 & 0.66 'dry’ \\
\hline Total engine weight/max. take-off weight & 0.045 & 0.13 \\
\hline Max. fuel weight/max. take-off weight & 0.43 & 0.40 \\
\hline Maximum wing loading $\left(\mathrm{N} / \mathrm{m}^{2}\right)$ & 7600 & 3400 \\
\hline
\end{tabular}

\section{The Modules}

In this section, the module for the fighter aircraft will be discussed in details first followed by the module for the large commercial aircraft.

Aircraft used in combat operations constitute the largest proportion of the various types of aircraft in the military inventory. They outnumber other aircraft types by roughly 3 to 1 as shown in the figure 1 below:

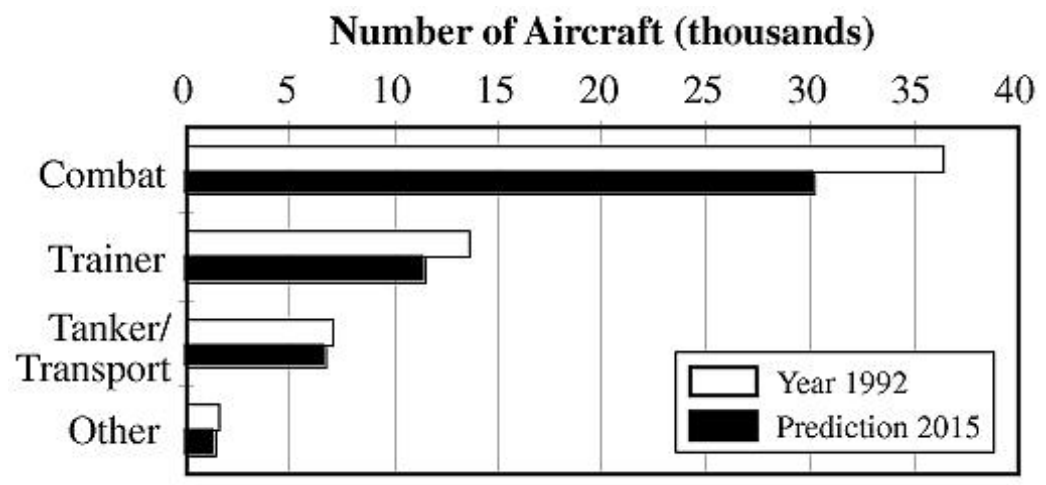

Figure 1 Comparison of the number of different types of aircrafts

Combat aircraft engines are designed to extract maximum performance even though it may shorten their lifetime. In terms of performance requirements, a higher thrust/weight (T/W) ratio engine is essential for this type of aircraft. As a result, new engines for fighter aircrafts will require higher-pressure ratios and higher peak temperatures. Reheat/afterburner operations are also an important requirement for combat aircraft engines.

The speed that the fighter operates will be limited to three Mach numbers $(0.9,1.5$ and 2.0$)$ at higher altitude while $M=0.9$ with the static condition will be used at sea level. Some default parameters used in the module are for F-15 and F-16. The F-15 has twin engines while the F-16 has only one; current thinking seems to prefer the two-engine layout, because of the added security in case of engine failure ${ }^{1}$. Therefore, two engines are selected for design choices given in the module. A screen shot of the module is given in Figure 2. 


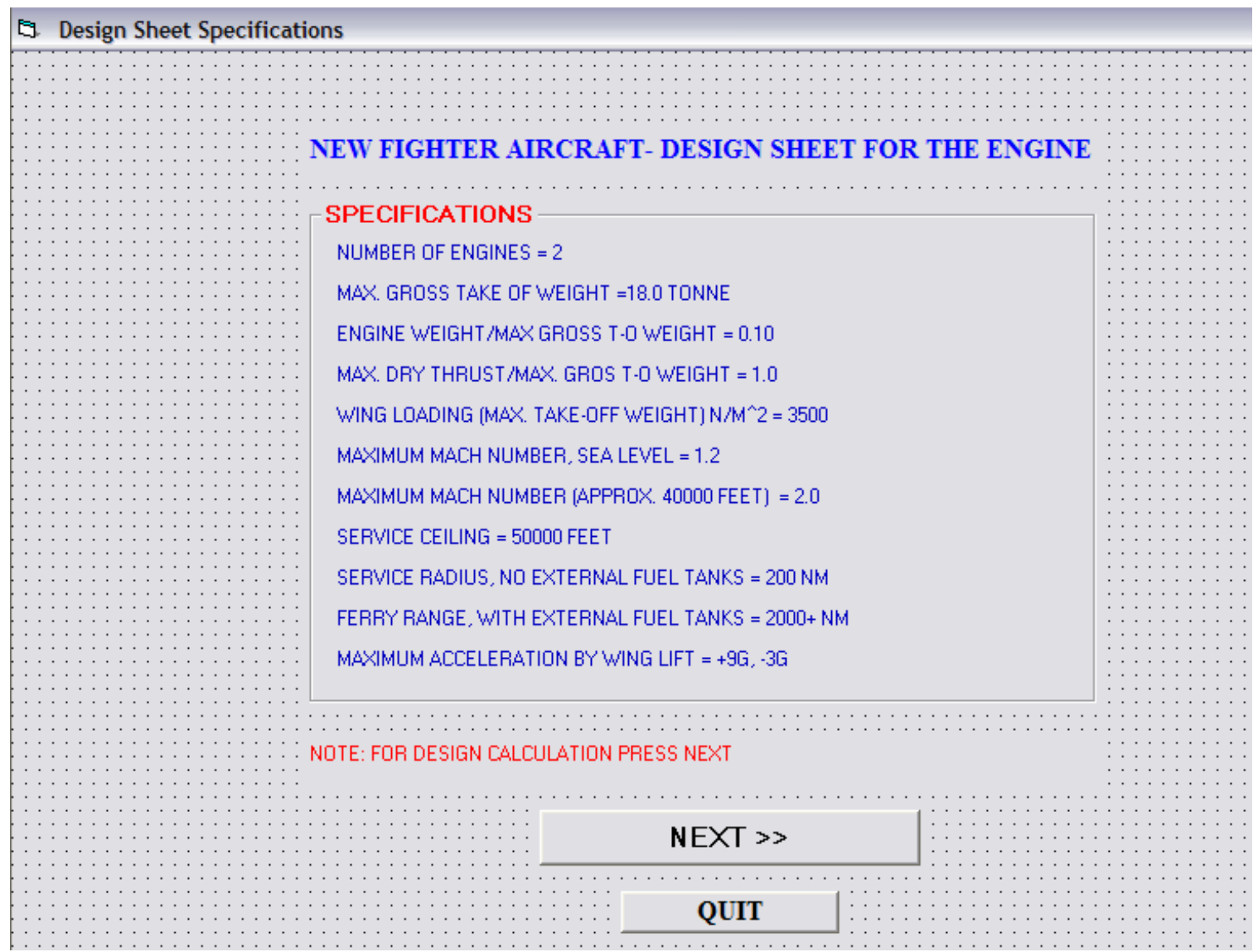

Figure 2 The opening screen shot of the fighter aircraft module

The equations and parameters given below and used in the VB module are taken from Cumpsty's book $^{1}$.

\section{Energy and Specific Excess power}

The energy state is the combined potential and kinetic energy given by

$$
E=m\left(g h+V^{2} / 2\right)
$$

with the specific energy

$$
E_{s}=g h+V^{2} / 2
$$

The ability to accelerate or climb depends on the excess thrust over and above that required to balance the drag in steady level flight. The measure of this is the excess thrust divided by the aircraft weight mg, which can e written

$$
\left(F_{N}-D\right) / m g
$$

where $F_{N}$ is the maximum net engine thrust and $\mathrm{D}$ is the aircraft drag. More conventionally, the above quantity is multiplied by the flight speed to give specific excess power, SEP, 


$$
S E P=V\left(F_{N}-D\right) / m g
$$

Eq. (4)

For the 'Dry' case, the thrust-weight ratio is 0.66 and the thrust is $58.3 \mathrm{kN}$ and for afterburning, the thrust-weight ratio is 1.00 and the corresponding thrust is $88.3 \mathrm{kN}$. A sample screen shot for calculating the thrust required is shown in Figure 3.

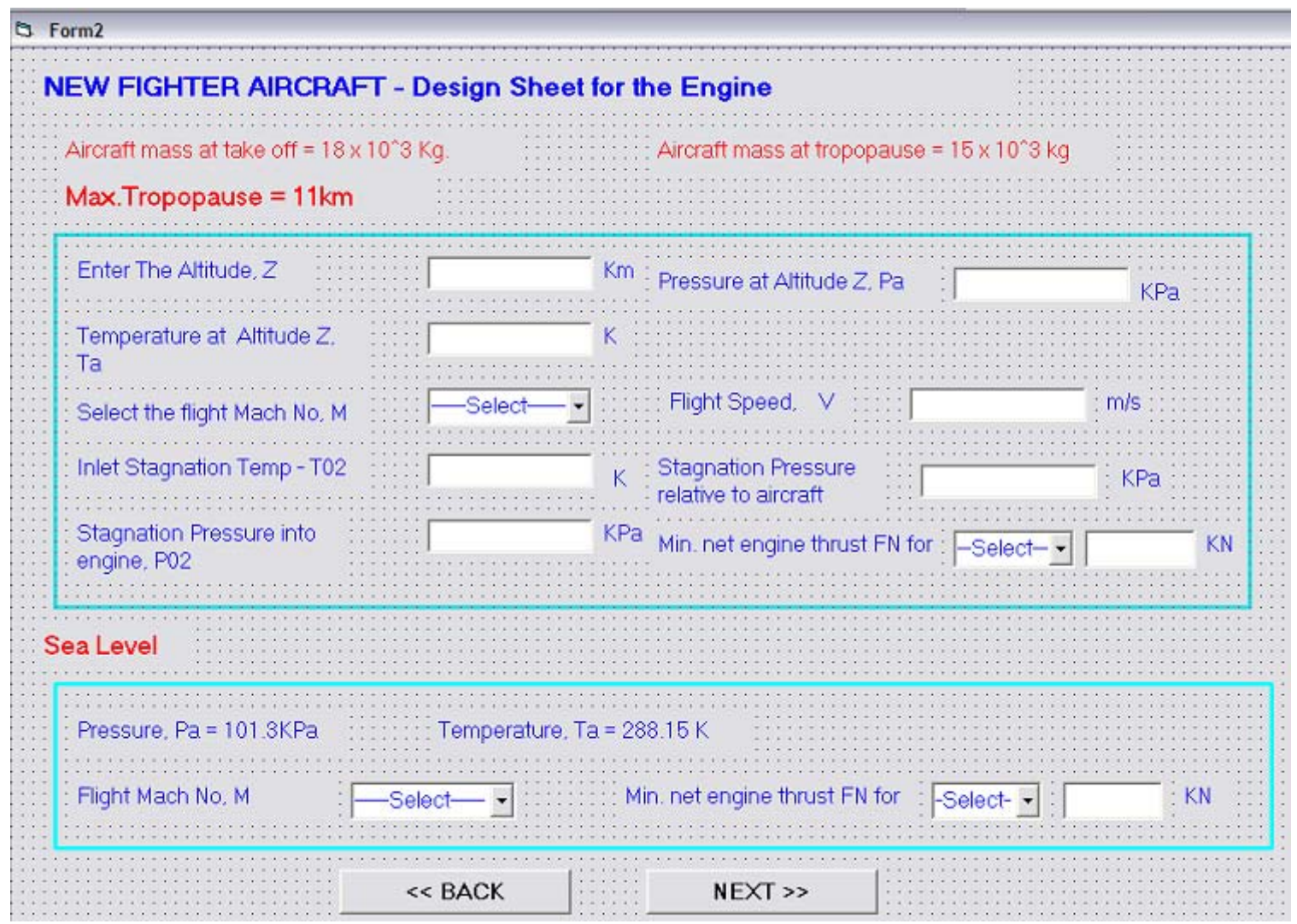

Figure 3 Thrust Calculation for given set of parameters

For a combat aircraft, the essential components are a LP compressor (referred to as the fan) driven by the single-stage LP turbine, and the core compressor driven by the single-stage HP turbine. 


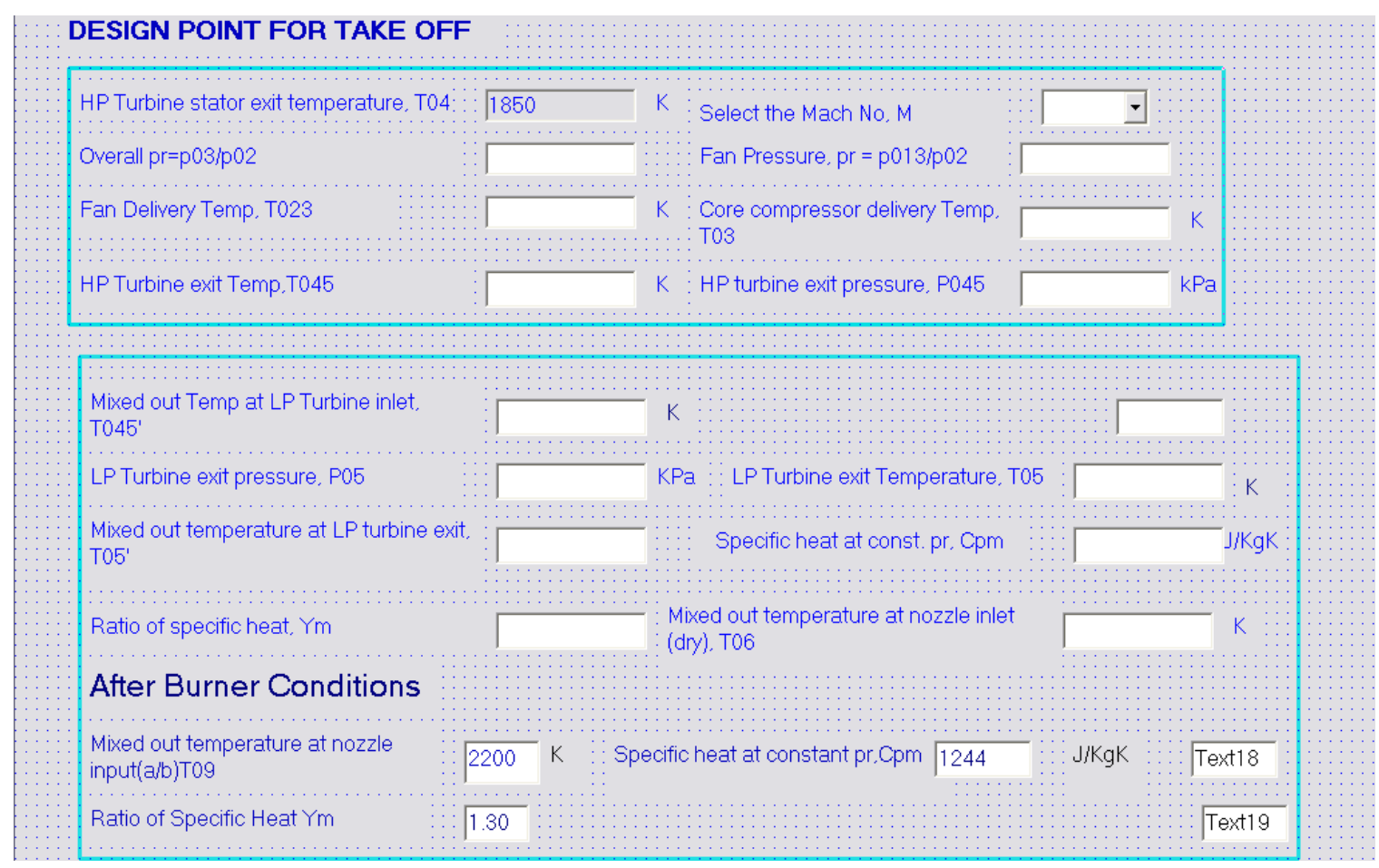

Figure 4 Determination of Parameters for different components of the engine

In addition, some parameters related to the combustor and the afterburner such as air and fuel flow rates need to be determined. These computations are done in the module screen shown below as Figure 5.

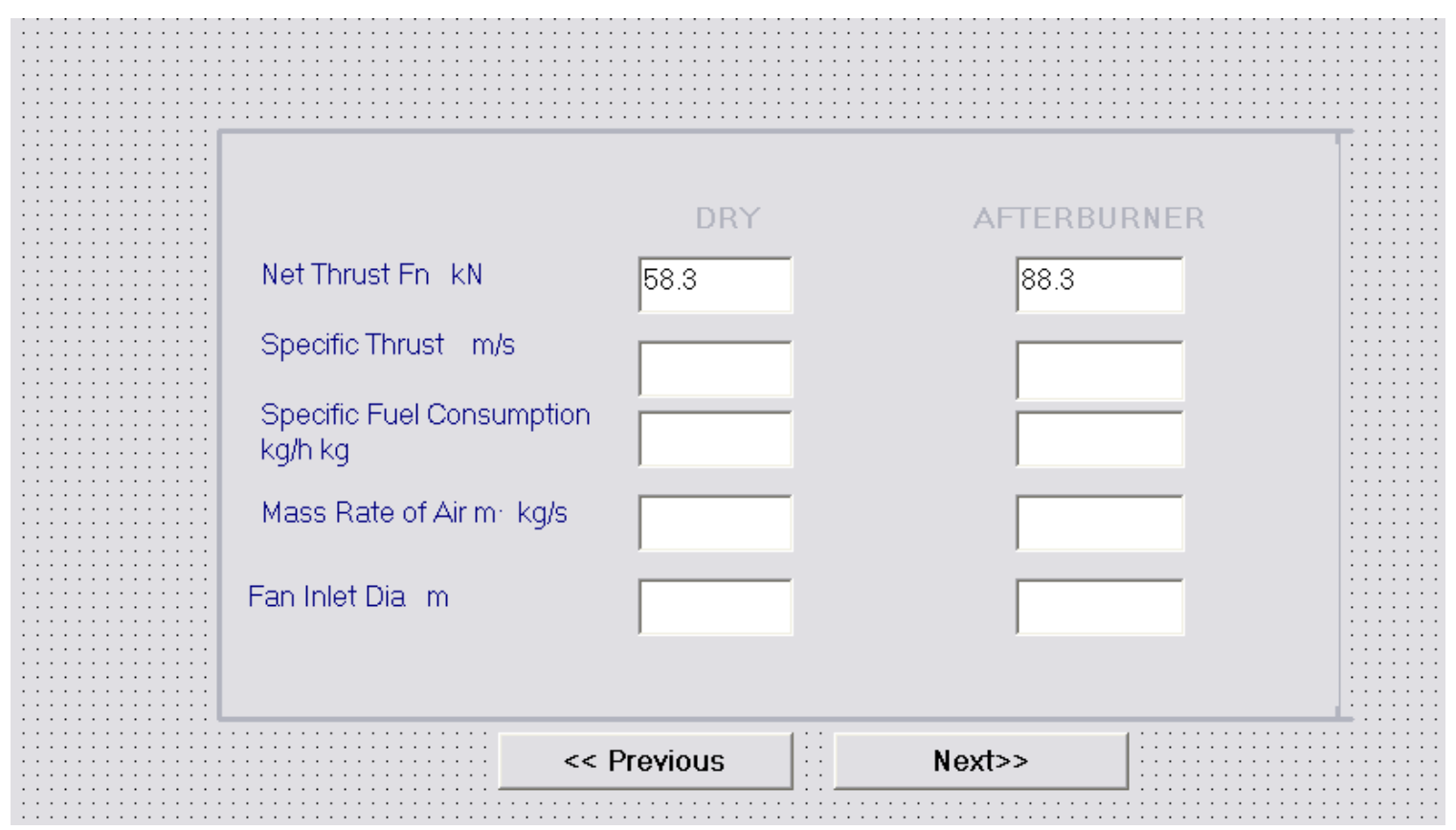

Figure 5 Determination of air and fuel flow rates

Proceedings of the 2009 ASEE Gulf-Southwest Annual Conference Baylor University

Copyright (C) 2009, American Society for Engineering Education 
The last parameters to determine for the design are the dimensions and velocities of the compressors and turbines that will be used in the detailed design of the blades. These are determined as shown in Figure 6. The detailed blade design is not covered in the present module but can be added to complement the present module.

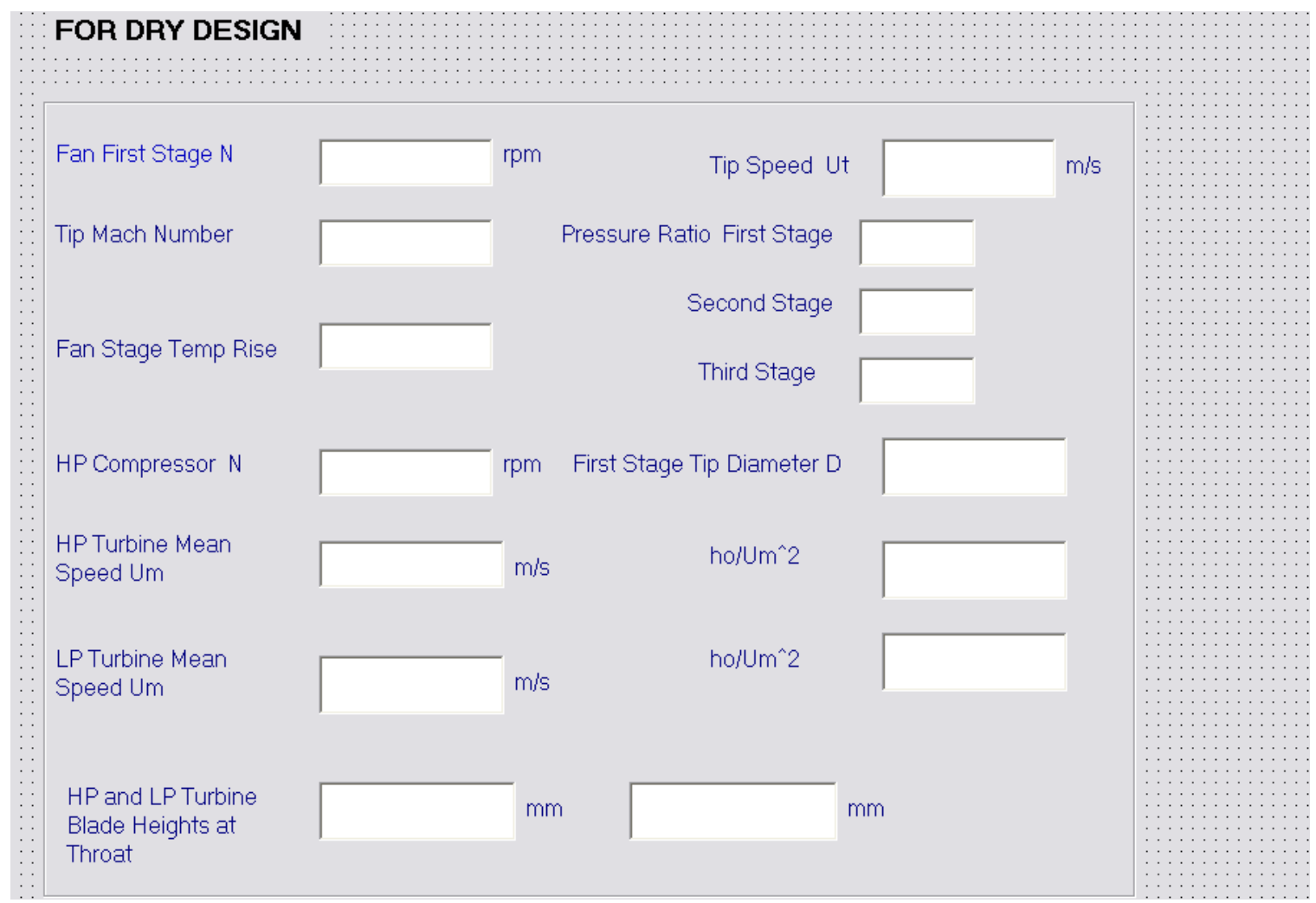

Figure 6 Determination of parameters related to compressors and turbines

Many of the computations are similar to those for fight aircraft but the main difference is in the form of bypass ratio in the commercial engines. Commercial engines have a bypass ratio of 5 to 9 with no use of the afterburner (ab). As a result, only two screens from the other modules for large commercial aircrafts are shown in Figures 7 and 8. 


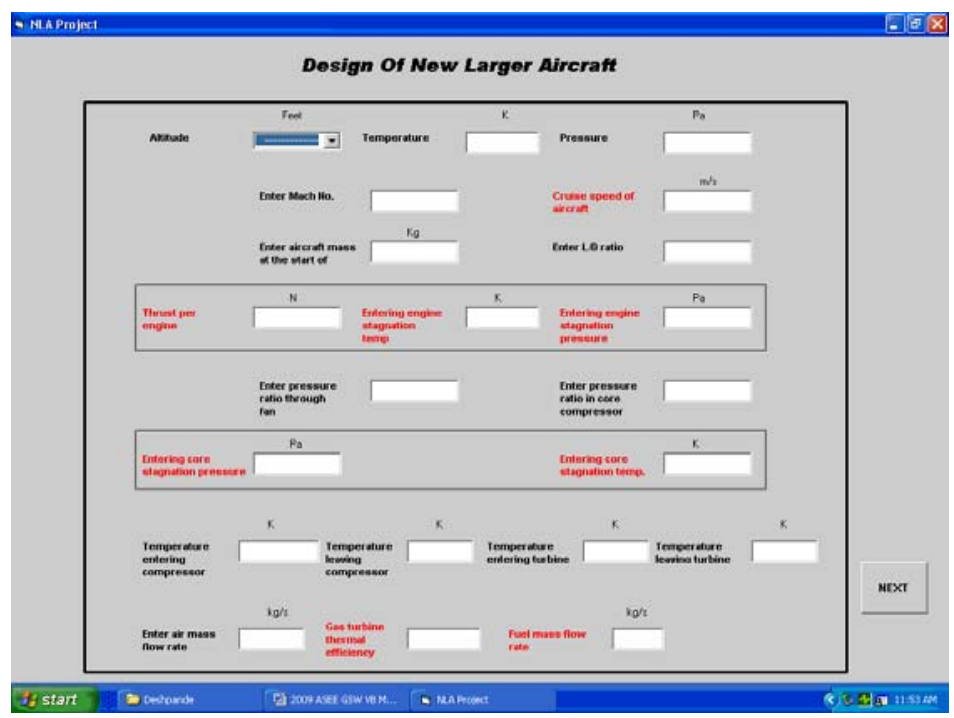

Figure 7 A sample screen of second VB module

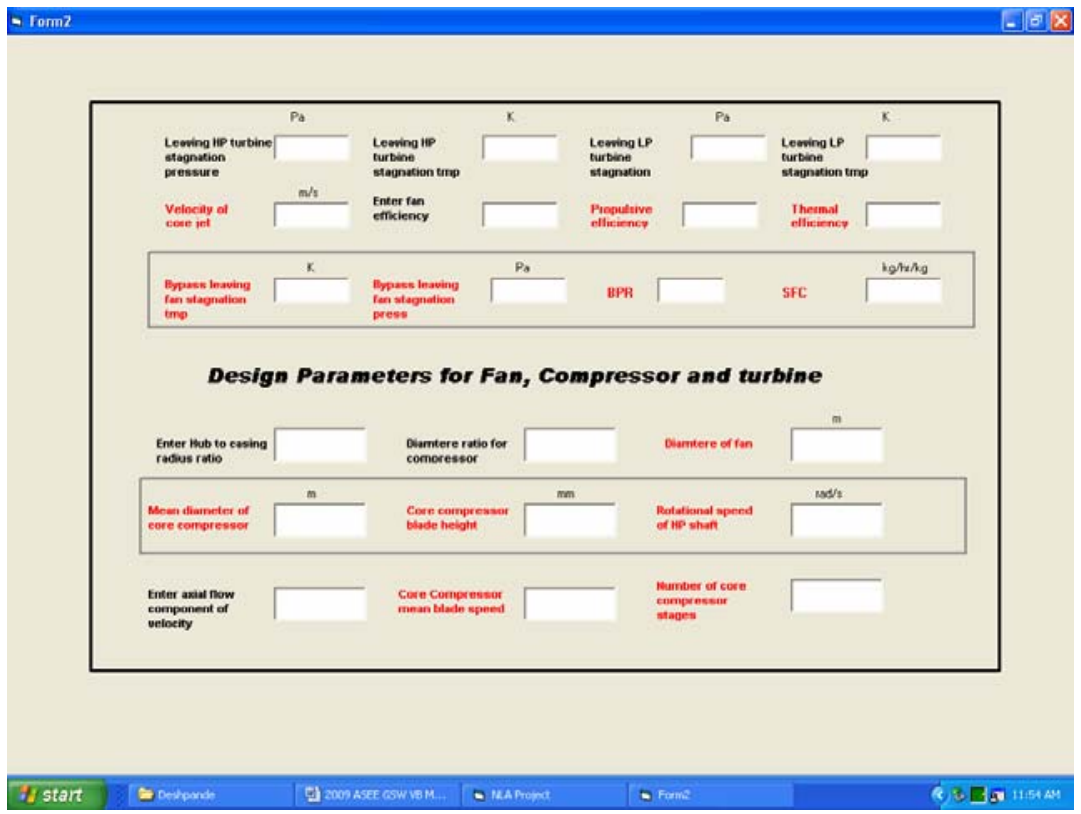

Figure 8 Another screen shot of the second VB module

\section{Current Status and Examples of Use}

The development of the modules has been completed but they are being debugged and tested for their performance and accuracy. The plan is to offer the new Propulsion course as an elective course in the Fall 2009 semester and use these modules in the implementation of student design projects. The use of the modules can be implemented in many ways especially for group design projects, and some examples are given below:

(a) The students can be given a set of parameters such as weight, thrust to drag ratio, etc, to design an engine.

(b) The students can perform a parametric study to determine the effect of a key variable on 
the performance, for example minimum fuel consumption for a given thrust to drag ratio. (c) The students can also compare the designs of two different types of aircrafts by using some common parameters between the two designs.

\section{Summary}

This paper describes the development of two Visual Basic modules that can be used in a typical propulsion course. The students can use these modules to design and analyze aircraft engines for either large commercial airplanes or fighter aircrafts in their study.

\section{References}

1. Cumpsty, N., 2003, “Jet Propulsion“", $2^{\text {nd }}$ Edition, Cambridge University Press.

2. http://www.grc.nasa.gov/WWW/K-12/airplane/bgp.html, accessed December 12, 2008.

3. http://www.stg.srs.com/SETD/PropulsionSoftware.htm, accessed December 12, 2008.

\section{KENDRICK AUNG}

Dr. Kendrick Aung is an Associate Professor in the Department of Mechanical Engineering at Lamar University. He received his Ph.D. degree in Aerospace Engineering from the University of Michigan in 1996. He has published over 80 technical papers and presented them in numerous national and international conferences.

\section{CHANG LI}

Dr. Li is an Assistant Professor in the Mechanical Engineering department at Lamar University in Beaumont, Texas. His research interests include heat transfer in gas turbine, gas turbine cooling, propulsion, and energy conservation. He has published over 50 technical papers and presented them in numerous national and international conferences. 